\title{
Src Kinase Inhibitor AP 23846
}

National Cancer Institute

\section{Source}

National Cancer Institute. Src Kinase Inhibitor AP 23846. NCI Thesaurus. Code C162533.

A novel small molecule Src family kinase inhibitor with potential antiang iog enic activity. Upon administration, Src kinase inhibitor AP23846 selectively binds to and stabilizes an inactive ATP-binding site conformation leading to reduced Src kinase activity. This may reduce the production of pro-angiog enic factors, vascular endothelial growth factor (VEGF) and interleukin (IL)-8. Src tyrosine kinases are upregulated in many tumor cells and play important roles in tumor cell proliferation, survival, migration, invasion and angiogenesis. 